\title{
Fabrication of Metallic Glass Layers on Al Alloys with Improved Corrosion Resistance and Micro-Hardness by Pulsed Electrical Discharge Treatment
}

\author{
Han Dai ${ }^{1,2}$, Jie Sun ${ }^{1}$, Zhutie $\mathrm{Li}^{2}{ }^{2}$ Junfeng Zhao ${ }^{1}$, Xinxiang Yu ${ }^{1, *}$, Hongjie Fang ${ }^{1}$ and \\ Junhao Chen ${ }^{2}$ \\ 1 Laboratory of Advanced Light Alloy Materials and Devices, Yantai Nanshan University, Longkou 265713, \\ China; daihan1985@189.cn (H.D.); sunjie19860304@163.com (J.S.); zhaojunfengcc@163.com (J.Z.); \\ h.j.fang@163.com (H.F.) \\ 2 Hang Xin Material Technology Co. Ltd., Longkou 264006, China; lizhutie9999@163.com (Z.L.); \\ chenjunhaoedu@163.com (J.C.) \\ * Correspondence: yuxinxiangcn@163.com; Tel.: +86-139-6383-0180
}

Received: 22 May 2018; Accepted: 6 June 2018; Published: 11 June 2018

\begin{abstract}
Pulsed electrical discharge (PED) is a method that has been employed to fabricate metallic glass (MG) layers on $\mathrm{Al}-\mathrm{Cu}-\mathrm{Mg}-(\mathrm{Zn})$ alloys. Abnormal $\mathrm{Al}$ and $\mathrm{Cu}$ element segregation has been found on the alloys vitrified surfaces after PED treatment. Surface element evaporation was found and proven to be the main reason for such significant segregation. Benefits to the evaporation of the non-corrosion resisting elements in the MG layers, the corrosion resistance, and the surface hardness of $\mathrm{Al}-\mathrm{Cu}-\mathrm{Mg}-\mathrm{Zn}$ alloys have been greatly improved. The average corrosion rates of $\mathrm{Al}-\mathrm{Cu}-\mathrm{Mg}-\mathrm{Zn}$ alloys with MG layers were reduced to about $2 \%$ of that without MG layers. Additionally, the surface hardness of Al-Cu-Mg-Zn alloys with MG layers was increased to $537.173( \pm 7) \mathrm{HV}_{0.1}$. PED treatment is a promising way to synthesize MG layers with controllable element proportions and distributions for wear- and corrosion-resistant coatings on traditional $\mathrm{Al}-\mathrm{Cu}-\mathrm{Mg}-\mathrm{Zn}$ alloys.
\end{abstract}

Keywords: metallic glass; $\mathrm{Al}$ alloys; segregation; surfaces

\section{Introduction}

$\mathrm{Al}$ alloys can develop a thin oxide layer to restrain their further corrosion [1]. However, this thin layer is reactive in damp environments. The susceptibility of $\mathrm{Al}$ alloys to corrosion may be further enhanced due to the cathodic activities of their intermetallic particles, such as the $\mathrm{Al}_{2} \mathrm{CuMg}$ and $\mathrm{Mg}(\mathrm{ZnCuAl})_{2}$ phase [2]. Many coating methods have been reported for fabricating surfaces on $\mathrm{Al}$ and its alloys, such as preparing a chromium [3] or superhydrophobic coating on the Al alloy [4]. However, these methods are still subject to some limitations, such as toxicity, a complicated procedure, and high cost.

Metallic glass (MG) as an excellent coating material is attracting a lot of attention because of its ultra-high hardness and corrosion-resistant properties [5]. Generally, the formation of metallic glass needs extremely high cooling rates and the methods that are used to generate it vary from conventional liquid splat-quenching to pulsed laser quenching to avoid crystallization [6]. However, these methods have either low cooling rates for the MG formation or require expensive instruments.

Pulsed electrical discharge (PED) treatment based on the spark erosion on a metal surface has been applied widely as the traditional metal cutting method [7]. Recently, PED has been employed to fabricate $\mathrm{Zr}$-, Ti-, and Fe-based amorphous layers on bulk metal as wear- and corrosion-resistant coatings [8] because of its extremely high heating (up to $10,000{ }^{\circ} \mathrm{C}$ ) and ultra-high cooling rates. Notably, the intense heating and cooling during PED treatment can also cause element distribution changes 
on the alloy's surface $[9,10]$, which could lead to significant changes in its physical and chemical properties, such as surface hardness, hydrophobicity, and corrosion resistance [11-13]. However, the PED-induced element distribution changes on metal surfaces have seldom been studied.

The Al-Cu-Mg-(Zn) alloys have been widely used in aerospace and military industries due to their superior combination of high specific strength and fracture toughness but weak glass-forming ability [14]. Herein, PED treatments were adopted to fabricate metallic glasses (MGs) and study their composition and element changes on the surface of $\mathrm{Al}-\mathrm{Cu}-\mathrm{Mg}-(\mathrm{Zn})$ alloys. Significant $\mathrm{Al}$ and $\mathrm{Cu}$ element segregation has been found in the vitrified coatings on their surfaces. Surface element evaporation has been found and proven to be the main reason for the abnormal element segregation through the PED process. In addition, enhancement of the microhardness and corrosion resistance of $\mathrm{Al}-\mathrm{Cu}-\mathrm{Mg}-(\mathrm{Zn})$ alloys has been obtained after PED treatment. This work provides a green and cheap way for the element proportions and distribution control in wear- and corrosion-resistant Al-based MG layers through PED treatment.

\section{Experimental}

Alloy ingots with nominal compositions of $\mathrm{Al}-\mathrm{Cu}-\mathrm{Mg}-(\mathrm{Zn})$ alloys were prepared by melting a mixture of the pure elements in an inert atmosphere. The experimental materials were prepared with pure $\mathrm{Al}, \mathrm{Mg}, \mathrm{Zn}$ and $\mathrm{Al}-\mathrm{Cu}$ master alloys by ingot metallurgy in a crucible furnace. The ingots of Al-Cu-Mg and Al-Cu-Mg-Zn were homogenized at $495^{\circ} \mathrm{C}$ and $470{ }^{\circ} \mathrm{C}$, respectively, for $24 \mathrm{~h}$, followed by air cooling to room temperature. The chemical compositions of the two alloys investigated are listed in Table 1. The plates were then cut by PED by the wire electrical discharge machine, which has a $0.18 \mathrm{~mm}$ molybdenum wire electrode. The moving rates of the wire electrode were controlled around $50 \mu \mathrm{m} / \mathrm{s}$ and the pulse interval $(7 \mu \mathrm{s})$ and working power $(64 \mathrm{~W})$ of the pulse duration were adopted. The microhardness of the polished and coated surface after PED treatment on the Al-Cu-Mg-Zn alloy was measured by Vickers hardness tester (HV-1000) under a load of $100 \mathrm{~g}$ for $15 \mathrm{~s}$. Corrosion behaviors of the polished and coated surfaces after PED treatment were prepared in $10 \%$ hydrochloric acid. Three pairs of samples were prepared to compare the hardness and corrosion resistance with and without MG layers.

Table 1. Chemical composition of the alloys.

\begin{tabular}{ccccc}
\hline Alloys & Zn (at. \%) & Mg (at. \%) & Cu (at. \%) & Al \\
\hline Al-Cu-Mg & - & 1.6 & 1.66 & Balance \\
Al-Cu-Mg-Zn & 2.88 & 1.75 & 1.11 & Balance \\
\hline
\end{tabular}

The surface morphologies of the treated alloys were measured by scanning electron microscopy (SEM) (JSM-6700F, JEOL Corp., Tokyo, Japan). The crystal structures were examined with an X-ray diffractometer (Ultima IV, Rigaku Corp., Tokyo, Japan) and high-resolution transmission electron microscopy (JEOL-2100F, JEOL Corp., Tokyo, Japan). The element segregation characterization was observed by an electron microprobe analysis (EPMA) (JXA-8230, JEOL Corp., Tokyo, Japan) instrument.

\section{Results and Discussion}

It is well known that PED is generally used as a traditional metal cutting method, which can instantly heat the surface of $\mathrm{Al}$ alloys far beyond their boiling points by the spark [14]. Under such high temperatures, the surface elements of $\mathrm{Al}$ alloys are vaporized and then carried away by the water fluid flow, as shown in Figure 1a. Then, the melted surface rapidly cools to room temperature by high-speed flow and the nature of the thermal diffusion to $\mathrm{Al}$ alloy substrate. The PED equipment and the samples in our case are presented in Figure 1b. Obviously, the surface color of the Al alloy became gray after PED treatment due to the formation of a recast layer. As shown in Figure 1c, the recast layer on the $\mathrm{Al}$ alloy was about $25 \mu \mathrm{m}$ without obvious cracks and had an amorphous state. 
The electoral electron diffraction provided similar results (inset in Figure 1d). The ultra-fast heating and cooling rates led to the formation of the MG layer on the surface of the $\mathrm{Al}$ alloys through the PED treatment. Figure 2 shows that the characteristic peaks of the $\mathrm{Al}$ and $\mathrm{AlCu}$ phases disappeared after PED treatment, which proves the complete vitrification on their surfaces during the ultra-fast cooling during the PED treatment.

As reported, the extreme heat generated and the gas produced by the electrolysis of water by the PED treatment led to the generation of bubbles (with diameters ranging from 10-100 $\mu \mathrm{m}$ ) near the surface of the $\mathrm{Al}$ alloys $[15,16]$, as shown in Figure 1a. The explosion of these bubbles pounded the $\mathrm{Al}$ alloy surface, which caused a shallow pit-shaped recast layer without obvious orientation, as shown in Figure 1c. Meanwhile, the heat generation induced rapid transformations of the three phases (vapor, liquid, and solid), simultaneously causing significant material evaporation and the formation of MG layers at the $\mathrm{Al}$ alloy surface. The bubble percussion and surface evaporation on the surface have a great influence on the element proportions and distribution in the MG layers of $\mathrm{Al}$ alloys.

To understand the PED-induced changes of the main element proportions and distributions in Al-based metallic glass, element mappings of the Al-Cu-Mg alloys as cast and after PED treatment were carried out by EPMA. As shown in Figure 3a, $\mathrm{Cu}$ and $\mathrm{Mg}$ in the Al-Cu-Mg alloy tended to be concentrated together at the solidification phase, whereas there does not seem to have been a segregation of $\mathrm{Al}$ and alloying elements $(\mathrm{Cu}, \mathrm{Mg})$ at the conventional solidification phase. It is easy to accept that the $\mathrm{Al}$ content in the region of the solidified phase is poorer in $\mathrm{Al}$ alloys, according to our common metallography cognition. However, the proportions and distributions of the Al-Cu-Mg alloys after PED treatment showed significant differences (Figure 3b). Serious element segregation of $\mathrm{Al}$ and $\mathrm{Cu}$ was observed on the MG layer of $\mathrm{Al}-\mathrm{Cu}-\mathrm{Mg}$ alloys after PED treatment, which shows almost an opposite position with that of the $\alpha-\mathrm{Al}$ and micro-alloying element $\mathrm{Cu}$ in the solidified phase. The element $\mathrm{Mg}$ was uniformly distributed in the $\mathrm{Al}$ matrix without element segregation. The serious reductions in the element proportions of $\mathrm{Cu}$ and $\mathrm{Mg}$ (Figure 3b) show significant differences in the atomic diffusion-induced element concentration in the traditional casting process $[17,18]$. Such PED-induced changes in the main element proportions and distributions in Al-based metallic glass cannot be understood from the traditional diffusion kinetics in solidification processes.
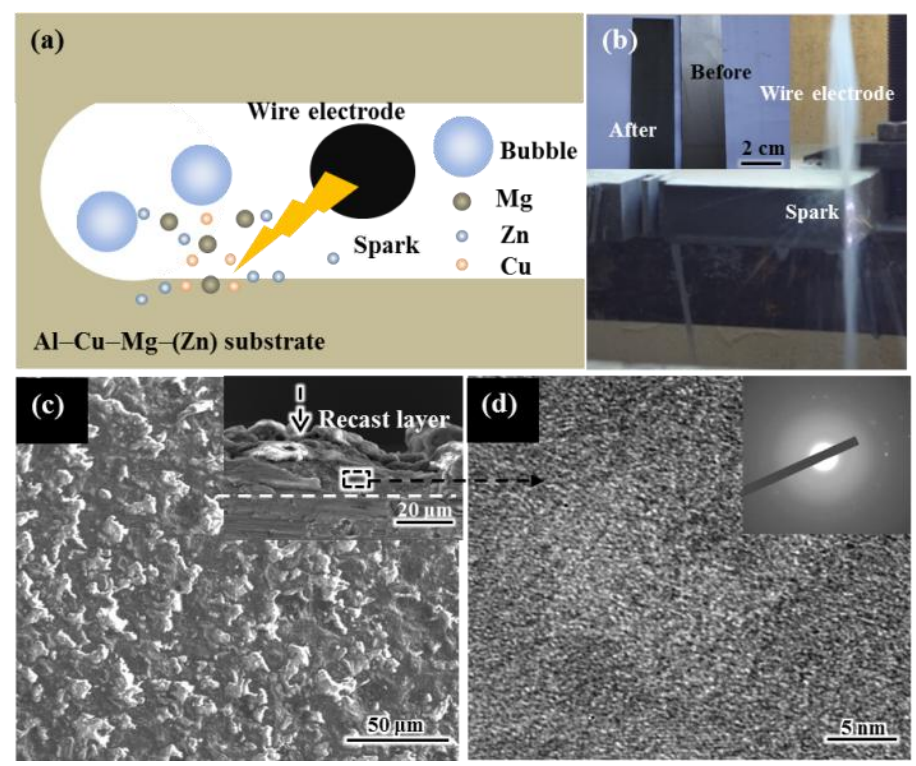

Figure 1. The schematic diagram of the pulsed electrical discharge equipment (a); the inset is Al-Cu-Mg-Zn samples with and without pulsed electrical discharge (PED) treatment (b). Scanning electron microscopy (SEM) image of the surface and the cross-section (c) of the Al-Cu-Mg-Zn after PED treatment; the inset is the cross-section view of the recast layer. (d) TEM image of the recast surface layer within the rectangular boxes and its selected area electron diffraction (SAED) pattern. 


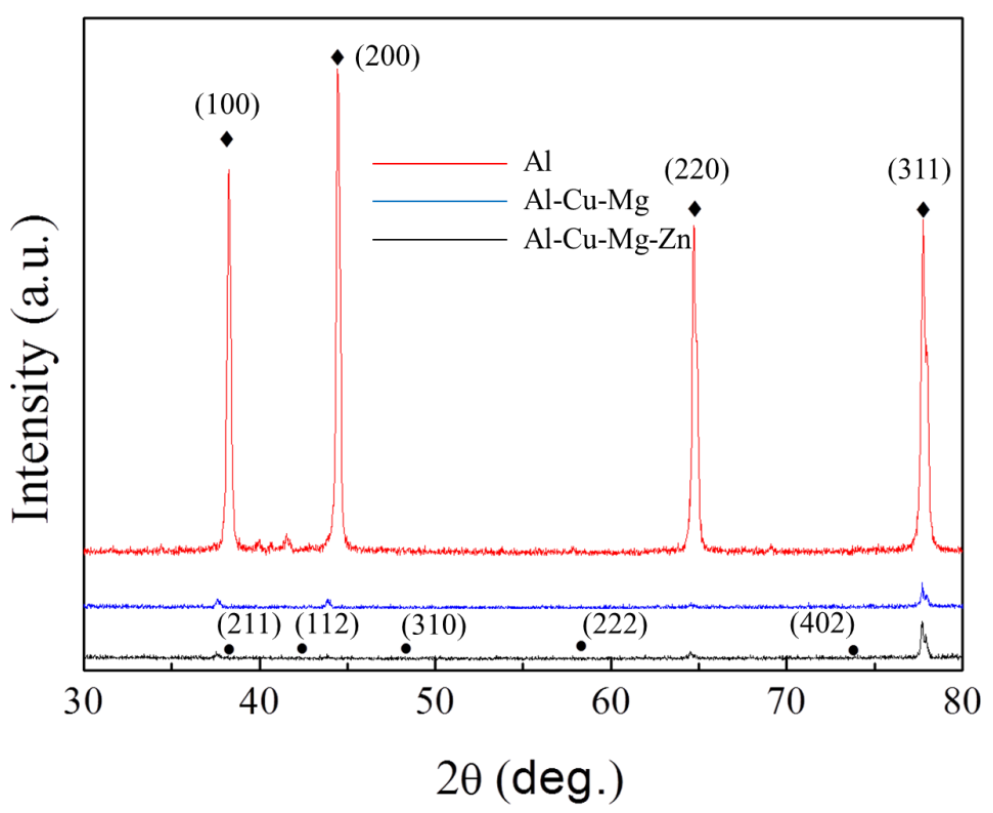

Figure 2. X-ray diffraction (XRD) patterns of the Al-Cu-Mg and $\mathrm{Al}-\mathrm{Cu}-\mathrm{Mg}-\mathrm{Zn}$ alloys by pulsed electrical discharge (PED) treatment with pure $\mathrm{Al}$ as reference.
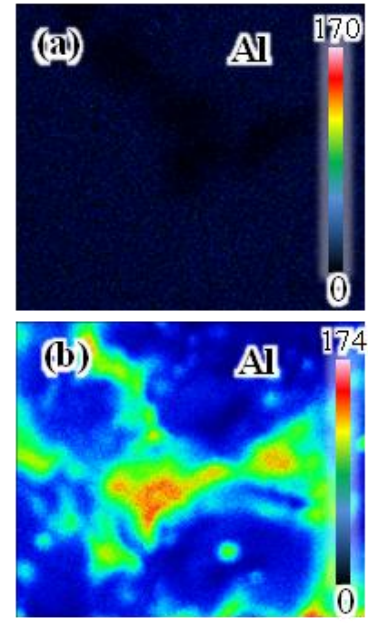
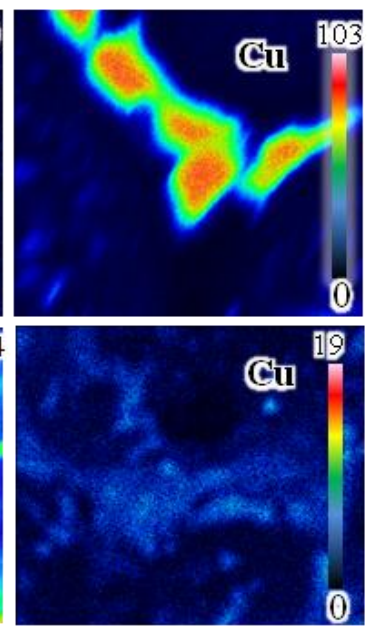
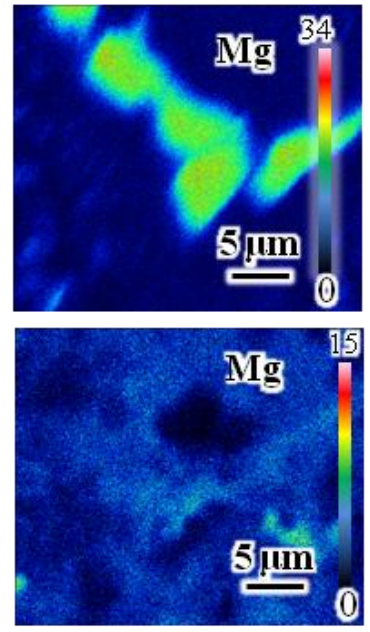

Figure 3. (a) Original element distribution of Al-Cu-Mg alloys by electron microprobe analysis (EPMA); (b) element distribution of Al-Cu-Mg alloys after PED treatment.

Besides the atomic diffusion, the reason for the change of surface composition can only be the detachment of elements from the surface of $\mathrm{Al}$ alloys. In our case, the detachment of surface elements of $\mathrm{Al}$ alloys can be attributed mainly to two possible ways. First, the bubble percussion peels the surface uniformly and cannot lead to the segregation of surface elements. Second, from the surface evaporation perspective, the boiling point-dependent co-evaporation provides us a possible way for understanding such abnormal element segregation after PED treatment. As shown in Table 2 [19], the boiling points of $\mathrm{Cu}$ and $\mathrm{Al}$ are similar and are much higher than $\mathrm{Mg}$. As a result, $\mathrm{Mg}$ would evaporate more easily than $\mathrm{Al}$ and $\mathrm{Cu}$ from the alloy's surface. Meanwhile, the similar high boiling points of $\mathrm{Cu}$ and $\mathrm{Al}$ lead to the co-evaporation of $\mathrm{Al}$ and $\mathrm{Cu}$ azeotrope during the PED heating and could cause significant element segregation of the $\mathrm{Al}$ and $\mathrm{Cu}$. Therefore, element evaporation rather than atomic diffusion caused the element proportion and distribution changes in the MG layers on an $\mathrm{Al}$ alloy surface during the PED treatment. 
Table 2. Melting point and boiling point of the elements.

\begin{tabular}{ccccc}
\hline Elements & $\mathbf{Z n}\left({ }^{\circ} \mathbf{C}\right)$ & $\mathbf{M g}\left({ }^{\circ} \mathbf{C}\right)$ & $\mathbf{C u}\left({ }^{\circ} \mathbf{C}\right)$ & $\mathrm{Al}\left({ }^{\circ} \mathbf{C}\right)$ \\
\hline Melting point & 419 & 650 & 1083 & 660 \\
Boiling point & 907 & 1108 & 2580 & 2500 \\
\hline
\end{tabular}

To confirm that evaporation induced the element proportion and distribution changes, $\mathrm{Zn}$ as a more volatile metal with 2.88 at. \% was added in the Al-Cu-Mg alloys. Significant element segregation of $\mathrm{Al}$ and $\mathrm{Cu}$ was also observed after $\mathrm{Zn}$ addition, as shown in Figure $4 \mathrm{~b}$. In contrast to Figure 4a, the residual quantity of $\mathrm{Zn}$ was quite low, which indicates that metals with a lower boiling point evaporate more easily from the alloy's surface with PED treatment.

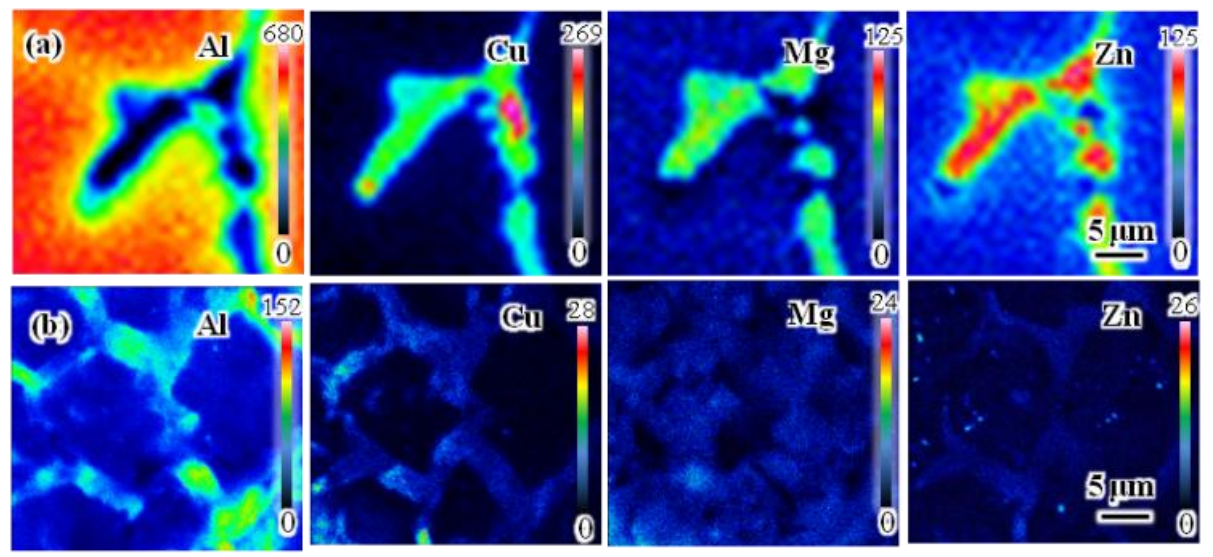

Figure 4. (a) Original element distribution of Al-Cu-Mg-Zn alloys by EPMA; (b) Al-Cu-Mg-Zn alloys after PED treatment.

Significant enhancement in corrosion resistance of the Al-Cu-Mg-Zn alloy has also been found after PED treatment. As shown in Figure 5a, two Al-Cu-Mg-Zn alloy samples with and without MG layers were dipped into $10 \mathrm{vol} \% \mathrm{HCl}$ solution. The sample with the MG layer showed less bubble generation than the sample without the MG layer. From the full immersion corrosion loss presented in Figure 5d, the sample with an MG layer showed significantly higher corrosion than without. It is well known that the corrosion behavior of an alloy depends primarily on the chemical activity of the alloy elements within the solution. $\mathrm{Mg}$ and $\mathrm{Zn}$ elements are more prone to corrosion in $\mathrm{HCl}$ solutions. As a result, the reduction in the element proportions of $\mathrm{Mg}$ and $\mathrm{Zn}$ in MG layers caused by surface evaporation significantly improved their corrosion resistance. Meanwhile, the dense atomic arrangement of MG layers on an $\mathrm{Al}-\mathrm{Cu}-\mathrm{Mg}-\mathrm{Zn}$ alloy led to relatively mild and uniform corrosion, which also improved their corrosion resistance. The average corrosion rates of the $\mathrm{Al}-\mathrm{Cu}-\mathrm{Mg}-\mathrm{Zn}$ alloys with a MG layer were reduced to about $\%$ of that without an MG layer. The formation of an MG layer not only provided a corrosion-resistant layer on the $\mathrm{Al}$ alloy surface but greatly enhanced the surface hardness. As shown in Figure 5b,c, the microhardness of the Al-Cu-Mg-Zn alloy was greatly enhanced from $90.086( \pm 2)$ (mean, standard deviation) $\mathrm{HV}_{0.1}$ to $537.173( \pm 7) \mathrm{HV}_{0.1}$ after the PED treatment. 
(a)
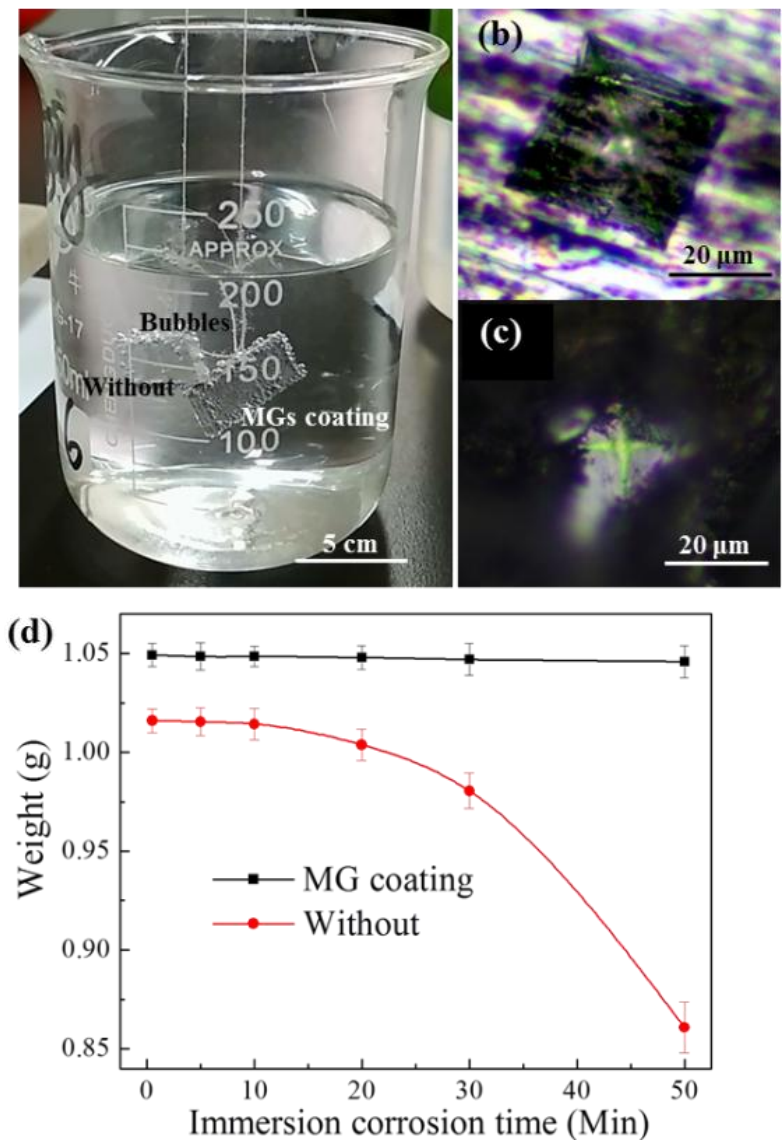

Figure 5. (a) Hydrochloric acid $(\mathrm{HCl})$ corrosion of the Al-Cu-Mg-Zn alloy with and without an MG layer; microhardness of the Al-Cu-Mg-Zn alloy without (b) and with (c) MG layers; (d) weightlessness of the Al-Cu-Mg-Zn alloy with and without MG layers in $10 \mathrm{vol} \% \mathrm{HCl}$ solution.

\section{Conclusions}

Abnormal $\mathrm{Al}$ and $\mathrm{Cu}$ element segregation has been discovered in the $\mathrm{Al}-\mathrm{Cu}-\mathrm{Mg}-(\mathrm{Zn}) \mathrm{MG}$ layers through the PED treatment. Surface element evaporation has been found and proven to be the main reason for such significant surface element segregation. Beneficial to the evaporation of the non-corrosion resisting elements in the MG layers, the average corrosion rates of $\mathrm{Al}-\mathrm{Cu}-\mathrm{Mg}-\mathrm{Zn}$ alloys with MG layers were reduced to about $2 \%$ of that without MG layers. Additionally, the surface hardness of Al-Cu-Mg-Zn alloys with MG layers was enhanced from $90.086( \pm 2) \mathrm{HV}_{0.1}$ to $537.173( \pm 7) \mathrm{HV}_{0.1}$. As a result, PED treatment provides us a possible way for the element proportion and distribution control in wear- and corrosion-resistant Al-based MG layers.

Author Contributions: Conceptualization, H.D.; Methodology, J.S.; Validation, X.Y.; Investigation, J.Z.; Resources, Z.L. and J.C.; Data Curation, H.F.; Writing-Original Draft Preparation, H.D.; Writing-Review \& Editing, H.D.; Supervision, X.Y.; Project Administration, H.D. and X.Y.

Funding: This research were funded by (A Project of Shandong Province Higher Educational Science and Technology Program) grant number (J17KA043, J17KB076); (Natural science foundation of Shandong province, China) grant number (ZR2017PEM005).

Acknowledgments: This research was support by Caiqiong Li for logistical services.

Conflicts of Interest: The authors declare no conflict of interest. 


\section{References}

1. Ghahremaninezhad, A.; Dolati, A. A study on electrochemical growth behavior of the Co-Ni alloy nanowires in anodic aluminum oxide template. J. Alloys Compd. 2009, 480, 275-278. [CrossRef]

2. Singh, S.S.; Schwartzstein, C.; Williams, J.J.; Zhao, X.H.; DeCarlo, F.; Chawala, N.; Singh, S.S.; Schwartzstein, C.; Williams, J.J. 3D microstructural characterization and mechanical properties of constituent particles in Al 7075 alloys using X-ray synchrotron tomography and nanoindentation. J. Alloys Compd. 2014, 602, 163-174. [CrossRef]

3. Li, L.L.; Whitman, B.W.; Munson, C.A.; Estrada, R.; Matzdorf, C.A.; Swain, G.M. Structure and Corrosion Performance of a Non-Chromium Process (NCP) Zr/Zn Pretreatment Conversion Coating on Aluminum Alloys. J. Electrochem. Soc. 2016, 163, C718-C728. [CrossRef]

4. Zheng, S.L.; Li, C.; Fu, Q.T.; Li, M.; Hu, W.; Wang, Q.; Du, M.P.; Liu, X.C.; Chen, Z. Fabrication of self-cleaning superhydrophobic surface on aluminum alloys with excellent corrosion resistance. Surf. Coat. Technol. 2015, 276, 341-348. [CrossRef]

5. Wu, G.; Liu, Y.; Liu, C.; Tang, Q.H.; Miao, X.S.; Lu, J. Novel multilayer structure design of metallic glass film deposited $\mathrm{Mg}$ alloy with superior mechanical properties and corrosion resistance. Intermetallics 2015, 62, 22-26. [CrossRef]

6. Lin, C.J.; Spaepen, F. Fe-B glasses formed by picosecond pulsed laser quenching. Appl. Phys. Lett. 1982, 41, 721-723. [CrossRef]

7. Shi, W.T.; Liu, Z.D.; Qiu, M.B.; Tian, Z.J. Wire tension in high-speed wire electrical discharge machining. Int. J. Adv. Manuf. Technol. 2016, 82, 379-389.

8. Zuo, L.; Pang, S.J.; Zou, S.F.; Li, H.F.; Zhang, T. Surface vitrification of alloys by pulsed electrical discharge treatment. J. Alloys Compd. 2017, 707, 148-154. [CrossRef]

9. Proskurovsky, D.I.; Rotshtein, V.P.; Ozur, G.E.; Markov, A.B.; Nazarov, D.S.; Shulov, V.A.; Ivanov, F.Y.; Buchheit, R.G. Pulsed electron-beam technology for surface modification of metallic materials. J. Vac. Sci. Technol. A 1998, 16, 2480-2488. [CrossRef]

10. Lukes, P.; Locke, B.R. Plasmachemical oxidation processes in a hybrid gas-liquid electrical discharge reactor. J. Phys. D Appl. Phys. 2005, 38, 4074-4081. [CrossRef]

11. Bae, W.G.; Song, K.Y.; Rahmawan, Y.; Chu, C.N.; Kim, D.; Chung, D.K.; Suh, K.Y. Fabrication and analysis of functionalized metallic surface. ACS Appl. Mater. Interfaces 2012, 4, 3685-3691. [CrossRef] [PubMed]

12. Köster, U. Surface crystallization of metallic glasses. Mat. Sci. Eng. 1998, 97, 233-239. [CrossRef]

13. Pang, S.J.; Zhang, T.; Asami, K.; Inoue, A. Synthesis of Fe-Cr-Mo-C-B-P bulk metallic glasses with high corrosion resistance. Acta Mater. 2002, 50, 489-497. [CrossRef]

14. Tosun, N.; Cogun, C. An investigation on wire wear in WEDM. J. Mater. Process. Technol. 2003, 134, $273-278$. [CrossRef]

15. Woloszko, J.; Stalder, K.R.; Brown, I.G. Plasma characteristics of repetitively-pulsed electrical discharges in saline solutions used for surgical procedures. IEEE Trans. Plasma Sci. 2002, 30, 1376-1383. [CrossRef]

16. Dai, H.; Wang, T.Y.; Li, M.C. Spotlight on ultrasonic fracture behaviour of nanowires: Their size-dependent effect and prospect for controllable functional modification. RSC Adv. 2016, 6, 72080-72085. [CrossRef]

17. Jia, M.; Zheng, Z.; Gong, Z. Microstructure evolution of the $1469 \mathrm{Al}-\mathrm{Cu}-\mathrm{Li}-\mathrm{Sc}$ alloy during homogenization. J. Alloys Compd. 2014, 614, 131-139. [CrossRef]

18. Deng, Y.; Yin, Z.; Cong, F. Intermetallic phase evolution of 7050 aluminum alloy during homogenization. Intermetallics 2012, 26, 114-121. [CrossRef]

19. Grosse, A.V. The temperature range of liquid metals and an estimate of their critical constants. J. Inorg. Nucl. Chem. 1961, 22, 23-31. [CrossRef]

(C) 2018 by the authors. Licensee MDPI, Basel, Switzerland. This article is an open access article distributed under the terms and conditions of the Creative Commons Attribution (CC BY) license (http:/ / creativecommons.org/licenses/by/4.0/). 